\title{
How is nutrition linked to income, agriculture and education?
}

\author{
Sayed Mohammad Naim Khalid
}

Independent Food Affairs Consultant, $5^{\text {th }}$ district, Kabul, Afghanistan A R T I C L E I N F O A B S T R A C T

Article history:

Received 07 August 2015

Accepted 31 January 2015

Available online, ISSN: 2148-127X

Keywords:

Agriculture

Nutrition

Education

Developing countries

Income

${ }^{*}$ Corresponding Author:

E-mail: sayednaim@outlook.com
Agricultural development is now expected to proceed in a way that maximizes opportunities to improve health and nutrition. Accordingly, the term "nutrition-educationagriculture linkages" describes the set of relationships that shows the mutual dependence of nutrition, education and agriculture. Changes in nutrition or education status are expected to affect agricultural production; conversely changes in the agricultural sector can have significant effects on individual health and nutritional status. Professionals are trained in nutrition or agriculture, but very few will be trained in both. It is therefore difficult to begin discussions on nutrition-focused agricultural programs and policies. How do we begin to identify these linked outcomes? And how do we begin to think about ways to impact factors that are outside of our sector of expertise? This paper provides a simple framework for thinking critically about education, agriculture, income and nutrition linkages. The purpose is to help readers identify the linkages of greatest importance to their goals and to begin thinking about how to take steps toward integrating programs more effectively.

\section{Introduction}

Afghanistan is country which is said to be dependent on agriculture hugely. In this sector around $80 \%$ of the population is busy. Agriculture is the main source of income and satisfying people food needs in this country (Kawasaki et al., 2012). Recently there have been renewed calls for greater integration of nutrition and agriculture policy which might not happen only in Afghanistan but around the developing world. The reasons are many, but in general, good nutrition, and by extension, good health, are no longer seen as only outcomes of successful development. Rather, health and nutrition are increasingly framed as critical inputs to achieving economic growth and poverty reduction. The World Bank, for example, speaks of repositioning nutrition within the development agenda. Stating that malnutrition "slows economic growth and perpetuates poverty" the World Bank presents improved nutrition as "essential to reducing extreme poverty" (Chung, 2012). There are three main ways through which agriculture influence the nutritional status of individuals: (1) increased incomes and lower food prices, which permit increased food consumption; (2) effects on the health and sanitation environment at the household and community levels, which may increase or reduce morbidity; and (3) effects on time allocation patterns particularly of mothers which may increase or reduce time spent on nurturing activities - time that is often related to women's control over household income and is an important determinant of woman's nutritional status (Kennedy and Bouis, 1993).
There is currently considerable momentum around the importance of the agriculture nutrition nexus as a means of improving nutritional status. In 2011, IFPRI sponsored a conference in New Delhi called "Leveraging Agriculture for Nutrition and Health", which brought together nearly 1,000 experts, policy makers, and practitioners to discuss the linkages between agriculture, health and nutrition, and the challenges and opportunities for leveraging agriculture to improve nutrition and health. A World Bank review of multiple food security programs highlighted the role of nutrition education in enhancing food security outcomes, clearly showing that food security alone does not improve nutritional status. The evidence for this integration is so compelling that the USAID initiative to reduce food insecurity and hunger, known as Feed the Future, integrates nutrition education with agriculture to meet outcome goals of improved child nutritional status and dietary diversity of target populations. Results of this combined effort will be available in four to five years (McNulty, 2013).

The source of the nutrition education actions can also vary, involving the public sector, the private sector, civil society and public-private initiatives. Actions may involve a wide array of different foods and nutrients, from fruits and vegetables to dairy, from dietary fibre to fats, or be generic to healthy eating. There are thus four key variables to nutrition education actions: core aim; setting; source; and food/nutrient. In practice, it is difficult to separate out nutrition actions into these specific categories 
because they tend to be inter-linked (Hawkes, 2013). For example, they may involve both the provision of information and changing the environment, both the public and private sectors, and take place across a range of settings. However, they can be broadly categorized into four:

- Public awareness campaigns;

- Education in specific settings;

- Skills training;

- Changes to the food environment.

This literature review is aimed at bridging the evidence gap on the status and linkage of education and agriculture with nutrition. In addition, I take advantage of some studies to find relation of income to nutrition. The main questions to be answered during this study include: Are there evidences of linkage between education to nutrition, agriculture to nutrition and income to nutrition?

\section{Impact of Agriculture on Nutrition}

Agriculture and nutrition are linked in many ways. People have long recognized the most obvious connection-food security is one of the three pillars of good nutrition, along with good care and good health. The pathway through which agriculture affects nutrition are well documented. Improved nutrition in turn supports the agriculture sector by enhancing rural people's ability to undertake the strenuous tasks involved in small scale farming. The links between improved nutrition status and improved work capacity productivity are clear (Oshuag and Haddad, 2002). But the women role in agriculture production in Afghanistan is debatable and there is no study yet to show the relationship between the hours a woman works and how much she benefits from agriculture development.

The 1996 World Food Summit definition of food security creates the space for increased collaboration between agriculture and nutrition. The definition also strengthens the focus on the needs of consumers across different dimension: cultural (preferences), health (nutritionally adequate diet and safe food), and sustainability (FAO, 2006). The demand driven perspective can be visualized as shown in figure 1 .

\section{Linkage of Agriculture to Nutrition}

LANSA in 2013 identified and evidenced the linkage between agriculture and nutrition in Afghanistan by a conceptual framework developed by Gillespie, Harris and Kadiyala. Some of the linages can be as follow:

- Agriculture as a source of food (FAO, 2013; Meeker and Haddad, 2013), increases household availability and access to food from own production

- Agriculture as a source of income (World Bank, 2015; Meeker and Haddad, 2013), increases income from wages earned by agricultural workers or through the marketing of agricultural produce.

- Agriculture policy and food prices which affect supply-demand (Mahendra, 2012; Westcott, 2012) and a healthy agricultural sector can provide an employment buffer in times of economic crisis, especially in poorer countries (Thompson, n.d.)

- Influence of household decision making by women's socioeconomic status (LANSA, 2013)

- Women's ability to take care of family members mainly children during involvement in agricultural activities (World Bank, 2005; Meeker and Haddad, 2013), Women's social status and empowerment: women's participation in agriculture can affect their access to, or control over, resources and assets, and increase their power to make decisions on the allocation of food, health, and care within their household

- Women's own nutritional status (Meeker and Haddad, 2013)

- One can also view nutritional status as an input into agricultural growth. A common assumption is that better nourished individuals will be more productive (Kennedy and Bouis , 1993; Chung, 2012).

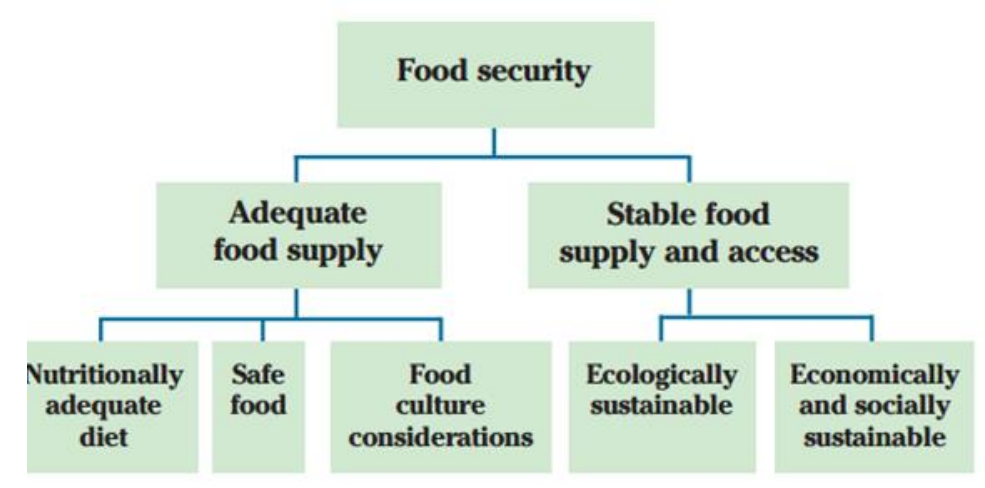

In the best interest of the consumer

Figure 1 Food Security: A common goal for agriculture and nutrition 


\section{Income and Education Linkage to Nutrition}

Education and nutrition have a cyclical relationship. Well-nourished children are better able to reach their academic potential, and girls with more formal education later give birth, and care for healthier and betternourished children. Educated girls can better understand and act on information, including use of health services, and are more empowered to make decisions such as contraception use, delaying marriage and first pregnancies, and longer birth intervals (MYCNSIA, 2013).

Nutrition education is an important measure to improve dietary habits and food choices, since poor dietary habits are the main reason for poor nutritional status of adolescents (Sachithananthan et al., 2012).

Poor infant feeding practices (IFP) directly or indirectly contribute to undernutrition, morbidity and mortality in infants. Sometimes, the lack of awareness and not poverty per se may be the likely cause of faulty IFP. Based on evidence, nutrition education (NE) empowers a mother to maximize the resources around her for the health of her child (Sethi et al., 2003).

Another study demonstrates that children of literate mothers had higher nutritional intakes than children of non-literate mothers. In addition, the schooling of girls can lead to a reduction of infertility, infant mortality rate, child practices and improve children's school performance (Sridhar, 2008).

Nutrition also has its effect on health and education. Good nutrition is the foundation for success in both school and life. By prioritizing nutrition in an informed and effective way, education programs can help all children achieve the healthiest and most productive life (MYCNSIA, 2013; Gelli, et al., 2014).

In a study in India conducted by (Bhagowalia et al., 2012) on linkages between nutrition and household incomes, as well as agricultural production, showed that the income gradient for under nutrition is indeed quite weak, although non-income determinants such as female secondary education, access to safe water and sanitation facilities, antenatal check-ups, and children's vaccinations all have significant effects on child nutrition. It also found some evidence that agricultural production conditions particularly irrigation and ownership of livestock substantially influenced household dietary diversity. The findings imply that income growth alone will likely have only modest impacts on malnutrition unless it is accompanied by improved health and education outcomes. For agriculture, the results also suggest some important nutritional entry points in terms of irrigation, crop diversification, and livestock ownership.

A number of studies find that overall economic growth-usually represented by GDP and per capita income - is only weakly associated with indicators of nutritional status and argue instead in favour of more direct nutrition intervention. In contrast another group found a positive and significant link between increased economic growth and nutritional status either unidirectional or bidirectional. Another study found that income growth had a positive effect on children's weightfor-age but also projected that similar income growth rates can produce significantly different reductions in malnutrition across countries over a period of about 25 year (Fan \& Brzeskand, 2011).

According to (WHO, 2014) Afghanistan's socioeconomic indicators show a mixed picture of progress and challenges, some of which remain a major concern. Life expectancy is low (60 years), despite a significant decline, infant, under-five and maternal mortality, respectively at 77 per 1000 live births, 99 per 1000 live births and 460 per 100000 live births are still high, and an extremely high prevalence of chronic malnutrition with $39 \%$ of all under 5 children and widespread occurrence of micro-nutrient deficiency.

Women in poorer households tend to participate in agricultural tasks outside the home more so than women in wealthier households (World Bank, 2005). Therefore, one would expect women in poorer households to have less time to manage the care, feeding, and health of their young children (MoPH, 2009). This would be one of the many reasons that children in poorer households are generally more undernourished than those in richer households (LANSA, 2013).

For mothers with a primary school education, the mortality of their children under five falls by nearly 50 percent, and for each additional year of schooling, infant mortality falls by an additional 10 percent (George W. Bush Institute of Women's Initiative, 2013). Furthermore, a recent study conducted by UNICEF in Afghanistan shows that illiterate mothers $(29.3 \%)$ were less likely to introduce complementary foods to their infants aged 6-8 months as compared to mothers with some level of schooling $(34.5 \%)$ or high level of schooling $(55.2 \%)$. Children from richest households (37.9\%) were more likely to start receiving complementary foods at an appropriate age than their counterparts belonging to lower wealth quintiles. The findings of the survey corroborated the close relationship between timely introduction of complementary feeding and income and education levels (UNICEF and MoPH, 2013). Likewise, (SC and IDS, 2012) states that nutrition and sanitation knowledge is important. Save the Children (SC) believes that limited knowledge about nutrition principles affects food choices and child feeding practices, which leads to malnutrition and growth failure (in particular among under-twos), which in turn leads to another generation of malnourished mothers. Women who are literate are less likely to be undernourished and less likely to have undernourished children. Moreover, a survey analysis from African countries including Malawi, Tanzania and Zimbabwe showed the primary education significantly reduce the rate of stunting, wasting and under nutrition in children (Makoka, 2013). A research result from Mexico indicates that there is a positive association between household wealth and child linear growth is larger in households with a more educated mother (Leroy et al., 2014). Generally, the different studies found out that preschool age and school age education and nutrition specific education are useful measures to reduce malnutrition 
effects (Jukes et al., 2002). In case nutritional status of children in school is not good, it hinders them from studying (Powell et al., 1998). A study conducted in Brazil shows that in adults the risk of obesity increased with increased income and the education level didn't affect the risk of obesity in in less developed areas while in developed areas it has slight effects (Marios et al., 2001). The following diagram can summarizes the entire relationship between income, agriculture and nutrition.

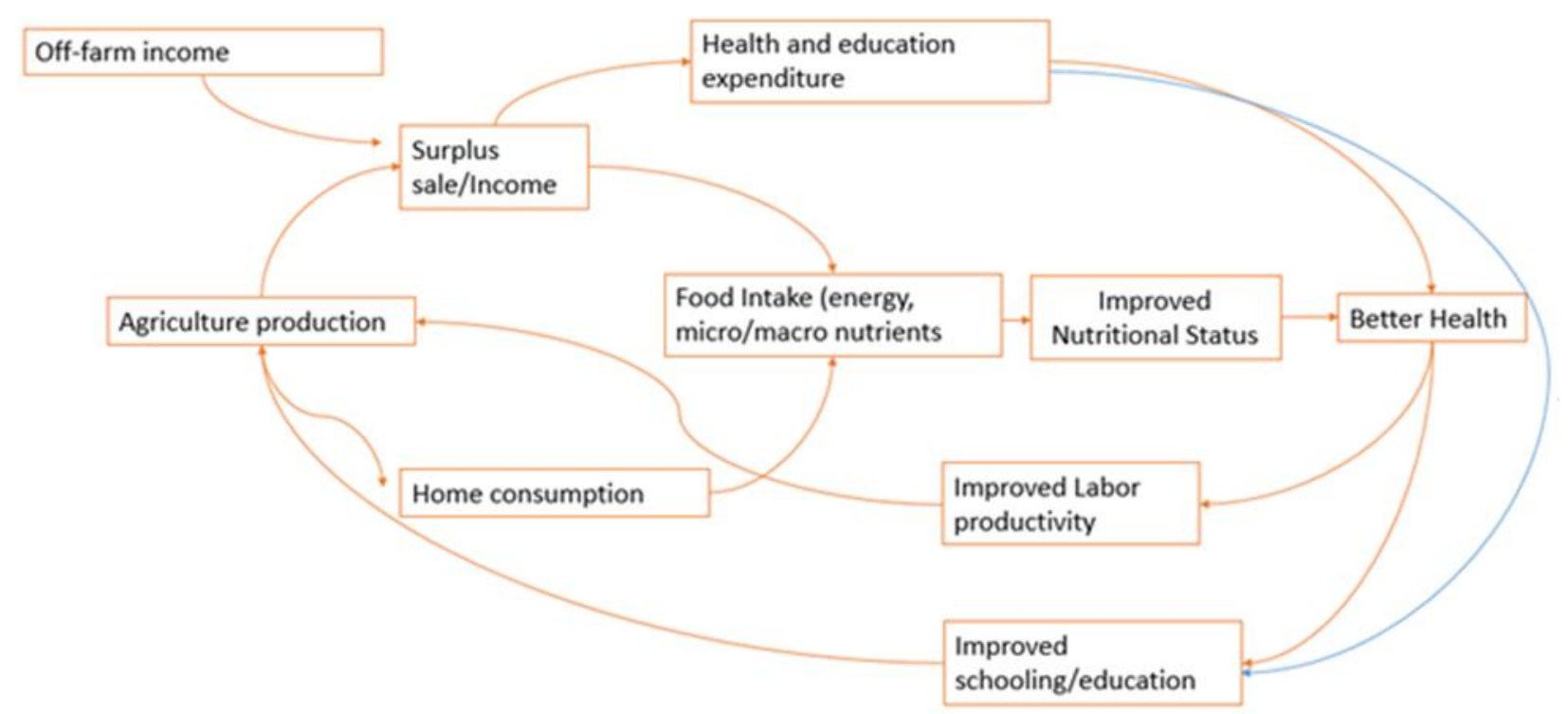

Figure 2 Ideal relationship of agriculture, education and income with nutrition

\section{Recommendations}

Further studies need to be done in Afghanistan context to understand the linkage between agriculture, education and nutrition in different regions. The effect of negative effects of women education and women working for income generating activities also needs further studies. The different effects of education in children under 5, school age children and adults also need further study because in most countries the results were mostly different from one another. The level of integration of agriculture, education and nutrition programs is not studied very well which needs to be worked on. It will open a door for clearer strategies and new projects by government and donors for integrating all three at the same time.

- Enable the efficient and effective collaboration in building multidisciplinary, integrated, nutrition and health promoting partnerships among schools, childcare centers, other child nutrition settings, and communities;

- Provide financial stability to state agencies to support nutrition education in schools and further integration of materials and training from nutrition programs;

- Allow each community to address its own unique nutrition education needs;

- Ensure local wellness policies are implemented and evaluated.

- Consumers ultimately determine what they eat and therefore what the food system produces. But governments, international organizations, the private sector and civil society can all help consumers make healthier decisions, reduce waste and contribute to the sustainable use of resources, by providing clear, accurate information and ensuring access to diverse and nutritious foods.

- Expand early childhood education programs that stimulate cognitive development and address nutrition. This can help offset developmental delays caused by undernutrition.

- Provide young girls with educational opportunities so they have the knowledge and ability to make informed and healthy choices, reducing the risk for undernutrition in future generations. Keeping adolescent girls in school helps delay the age of first pregnancy and contributes to their empowerment and access to better future earnings.

- Forge linkages between agriculture, education, health and social welfare to coordinate policy, advocacy, planning, and programming. A collaborative approach will ensure that cash transfer and other safety net programs are designed to maximize nutrition, health, and development outcomes for children; especially for infants and young children.

- Advocate for early agriculture, education and nutrition interventions, like fortified food supplements and school gardening within education initiatives. Integrate agriculture and nutrition into teacher training and school curricula. Together, they will maximize physical and cognitive development and health among children. 
- Agricultural production and productivity growth remain essential for better nutrition, but more can be done. Agricultural research must continue to enhance productivity, while paying greater attention to nutrient-dense foods such as fruits, vegetables, legumes and animal products and to more sustainable production systems. Production interventions are more effective when they are sensitive to gender roles and combined with nutrition education.

- At the end it is recommended that the policymakers consider the following guiding principles to have a greater nutrition impact (Meeker and Haddad, 2013):

a. Incorporate explicit nutrition objectives and indicators into their design, and track and mitigate potential harms

b. Assess the context

c. Target the vulnerable and improve equity

d. Empower women

e. Maintain or improve the natural resource base

f. Facilitate production diversification, and increase production of nutritious foods, improve processing, storage and preservation

g. Expand markets and market access for vulnerable groups, particularly for marketing nutrient rich foods

h. Incorporate nutrition promotion and education

i. Collaborate and coordinate with other sectors

- Finally, the following research gaps still exist in the agriculture-nutrition Nexus (Hawkes et al., 2012):

a. Research that considers the full pathway of change from agricultural inputs, practices, value chains, food environment to nutrition outcomes

b. The indirect effect of changes in agriculture on nutrition, through income and economic growth and associated changes in health and investments in health and education services

c. The effects of agricultural policy on nutrition as mediated through the value chain

d. Governance, policy processes and political economy as it relates to the development of agriculture for-nutrition policies and programs, the ability to implement them (and scale up) and for them to achieve their stated goals once implemented

e. The way research on agriculture and nutrition is conducted, such as the development of methodologies and appropriate metrics

f. Consumers as a broader target group, notably rural workers and non-rural populations

g. The rural and urban poor at risk from nutritionrelated non-communicable diseases

h. Cost-effectiveness

\section{Conclusion}

Increased attention to nutrition can enable the agriculture sector to better meet its own needs in many ways. It can enhance the antipoverty and nutrition impacts of agriculture and ensure greater support for agriculture as an important public good. This increased support is likely to lead to significant private returns to small scale farming. Increased attention to nutrition can also help farmers anticipate and meet the needs of consumers. The question is therefore not whether there should be close inter-linkage between agriculture and nutrition, but rather how to best achieve a fruitful marriage. Clearly, what is essential is a common goal or conceptual vision to guide both agriculture and nutrition in policy making, strategy development, and institutional innovation so that those commonalities can be realized for the benefit of poor consumers and poor farmers.

Finally, given the complexity of these linkages it is important to think beyond advocating for a single approach and to instead think about building a larger, coherent strategy that comprises many varied approaches. Understandably, any given government agency or development organization has its own strengths and areas of interest. But finding ways to cut across these experiential bases is important if we aim to affect nutritional status through agriculture and education.

\section{References}

Leroy J, Habicht JP, González de Cossío T, Ruel M. 2014. Maternal Education Mitigates the Negative Effects of Higher Income on the Double Burden of Child Stunting and Maternal Overweight in Rural Mexico. The Journal of Nutrition, Vol. 144(No. 5), $765-770$

Powell C, Walke S, Chang S, Grantham-McGregor S. 1998. Nutrition and education: a randomized trial of the effects of breakfast in rural primary school children. The American Journal of Clinincal Nutrition, Vol. 68(No. 4), 873-879.

Westcott P. 2012. USDA Agricultural Projections to 2021: Outlook No. (OCE-121). Washington, D.C.: USA: USDA.

Bhagowalia P, Headey D, Kadiyala S. 2012. Agriculture, Income, and Nutrition Linkages in India. The International Food Policy Research Institute, IFPRI Discussion Paper 01195.

Chung K. 2012. An introduction to nutrition-agriculture linkages: Research Report 72E. Republic of Muzambique: Ministry of Agriculture.

Fan S, Brzeska J. 2011. The nexus between agriculture and nutrtion: do growth patterns and conditional factors matter? 2020 Conference Paper (pp. 31-38). Washington DC: The International Food Policy Research Institute.

FAO. 2006. Food Security. Policy Brief(Issue 2), 1-4.

FAO. 2013. The state of food and agriculture: Food system for better nutrition. Rome: Italy: FAO.

Gelli A, Masset E, Diallo AS, Assima A, Hombrados J, Watkins K, Drake L. 2014. Agriculture, nutrition and education: on the status and determinants of primary schooling in rural Mali before the crises of 2012. International Journal of Educational Development, 39, 2015-225. doi:http://dx.doi.org/10.1016/j.ijedudev.2014.07.003

George W. Bush Institute's Women's Initiative. 2013. Invest in Afghan Women. TEXAS: USA: George W. Bush Institute.

Hawkes C. 2013. Promoting healthy diets through nutrition education and changes in the food environment: an international review of actions and their effectiveness. Rome: Nutrition Education and Consumer Awareness Group: FAO. 
Hawkes C, Turner R, Waage J. 2012. Current and Planned Research On Agriculture For Improved Nutrition: A Mapping And A Gap Analysis. LCIRAH.

Jukes M, Judith M, Method F, Sternberg R. 2002. Nutrition and Education: Brief 2 of 12. Geneva: In Nutrition: A Foundation for Development: UN/ACC/ACSN.

Kawasaki S, Watanabe F, Suzuki S, Nishimaki R, Takahashi S. 2012. Current Situation and Issues on Agriculture of Afghanistan. Journal of Arid Land Studies, 22(1), 345 -348.

Kennedy E, Bouis H. 1993. Linkages between agriculture and nutrition: implications for policy and research. Washington D.C.: International Food Policy Research Institute (IFPRI).

LANSA. 2013. Afghanistan Evidence Review: Agriculture and Nutrition Linkages. Retrieved Dec 2, 2014, from Leveraging Agriculture for Nutrition in South Asia (LANSA): http://lansasouthasia.org/lansa/sites/default/files/Afghanistan $\% 2$ 0Evidence\%20Review\%20Agriculture $\% 20$ and $\% 20$ Nutrition $\% 2$ OLinkages.pdf

Mahendra D. 2012. Agriculture-nutrition linkages and policies in India: Series No. 1184. International Food Policy Research Institute (IFPRI).

Makoka D. 2013. The Impact of Maternal Education on Child Nutrition: Evidence from Malawi, Tanzania, and Zimbabwe (DHS working paper 84). Lilongwe: Malawi: DHS/USAID.

Marios AC, Conde W, Popkin B. 2001. Independent Effects of Income and Education on the Risk of Obesity in the Brazilian Adult Population. The Journal of Nutrition, Vol. 131(No. 3), 881-886.

McNulty J. 2013. Challenges and issues in nutrition education. Background paper for the International Conference on Nutrition . Rome: Nutrition Education and Consumer Awareness Group: FAO. Retrieved from International Food Policy Research Institute.

Meeker J, Haddad L. 2013. A state of the art review of Agriculture Nutrition Linkage: An agridiet position paper. Cork, Ireland.: Agridiet project: Department of Food Business and Development, University College Cork.
MoPH. 2009. Public Nutrition Policy and Strategy 2010-2013. Kabul: Afghanistan.

MYCNSIA. 2013. Multi-sectoral Approaches to Nutrition: The case for investment in education programing. Maternal and Young Child Nutrition Security Initiative in Asia - UNICEF and EU.

Oshuag A, Haddad L. 2002. Nutrition and Agriculture. Genev: UN ACC/SCN.

Sachithananthan, V, Buzgeia M, Awad F, Omran R, Faraj A. 2012. Impact of nutrition education on the nutritional status. Nutrition \& Food Science, 42(3), $173 \quad$ - 180. doi:http://dx.doi.org/10.1108/00346651211228469

SC, IDS. 2012. Breif Paper Tackling Child Malnutrition. Save the Children's report, A Life Free from Hunger:Tackling child malnutrition, (pp. 1-4).

Sethi V, Kashyap S, Seth V. 2003. Effect of Nutrition Education of Mothers on Infant Feeding Practices. Indian Joumal of Pediatrics, 70(6), 463-466.

Sridhar, D. 2008. Linkages between Nutrition, Ill-Health and Education: Background paper prepared for the Education for All Global Monitoring Report 2009 , Overcoming Inequality: why governance matters . UNESCO.

Thompson B. n.d. Impact of the Financial and Economic Crisis on Nutrition - Policy and Programme Responses. Rome: NUTRITION AND CONSUMER PROTECTION DIVISION: FAO.

UNICEF, MoPH. 2013. National Nutrition Survey Afghanistan. Kabul:Afghanistan.

WHO. 2014. Country Cooperation Strategy at a glance: Afghanistan. Geneve: Swiss.

World Bank. 2005. Afghanistan National Reconstruction and Poverty Reduction - the Role of Women in Afghanistan's Future. Macro Graphics Pvt. Ltd.

World Bank. 2015. Agriculture \& Rural Development. Retrieved Jan 7, 2015, from World Bank Website: Data: http://data.worldbank.org/topic/agriculture-and-ruraldevelopment 